\title{
Impact of Surgical Ventricular Restoration on Cardiac Function, Ischaemic Mitral Regurgitation and Long-term Survival
}

Rizwan Attia $^{1^{*}}$, Hannah Flemming ${ }^{1}$, Katharina Schulte ${ }^{1}$, John Chambers ${ }^{2}$, Christopher Young ${ }^{1}$, Graham Venn $^{1}$ and Fikrat Shabbo $^{1}$

${ }^{1}$ Department of Cardiothoracic Surgery, 6th Floor East Wing, St Thomas' Hospital, Westminster Bridge Road, London, SE1 7EH, UK

${ }^{2}$ Department of Cardiology, 6th Floor East Wing, St Thomas' Hospital, Westminster Bridge Road, London, SE1 7EH, UK

"Corresponding author: Rizwan Attia, Department of Cardiothoracic Surgery, 6th Floor East Wing, St. Thomas' Hospital, Westminster Bridge Road, London SE1 7EH, UK, Tel: +44 (0) 2071882014; E-mail: rizwanattia@doctors.org.uk

Received September 13, 2014; Accepted December 17, 2014; Published December 19, 2014

Copyright: (C) 2015 Attia R, et al. This is an open-access article distributed under the terms of the Creative Commons Attribution License, which permits unrestricted use, distribution, and reproduction in any medium, provided the original author and source are credited

\begin{abstract}
Objectives: Adverse cardiac remodelling is a major cause of morbidity and mortality post myocardial infarction. The role of surgical ventricular restoration compared to medical and electrophysiological treatments has recently come under intense scrutiny. We aimed to evaluate 10 -year clinical outcomes of surgical ventricular restoration in our institution.
\end{abstract}

Methods: From January 2001 to 2011, surgical ventricular restoration was performed in 126 consecutive patients (M2.3: 1F), mean age 65.5 (44-86) years. All patients presented with angina, heart failure and/or ventricular tachycardia. Post-infarction left ventricular aneurysm was present in all patients and ischemic dilated cardiomyopathy with a large akinetic left ventricle in $11.6 \%$. The preoperative left ventricular ejection fraction was $33.1 \pm 8.9 \%$. Multi-vessel disease was present in $117 / 126(93 \%)$ patients. Mitral regurgitation more than grade +2 was found in 39/126(31\%). The mean Logistic EuroSCORE was $13.8 \pm 5.9 \%$. A minimum of two-year post-operative follow-up was obtained on all patients.

Results: Most patients underwent endoventricular or elliptical patch repair; $94 \%$ had concomitant coronary revascularisation with a median of 2 grafts and $5 \%$ had mitral valve repair. Intra-aortic balloon pump was placed preoperatively in 24/126 (19\%) patients while 21/126 (17\%) needed inotropic support for more than $24 \mathrm{~h}$. Postoperative stroke occurred in 2 patients. In-hospital mortality was $7 / 126(5.5 \%)$. All cause cardiovascular mortality at ten years was $12 / 126(9.5 \%)$. Mean follow-up in operative survivors was $8.2 \pm 1.2$ years. Actuarial survival was $95.3 \%, 90.6 \%$, $86.3 \%$ and $79.1 \%$ at 1 -month, 1,5 and 10 -years. Echocardiographic follow-up demonstrated a reduction in the mean left ventricular end-diastolic volume and left atrial diameter. Ejection fraction improved over first year from 33.1 \pm 8.9 to $45 \pm 8.6 \%(P<0.006)$.

Conclusions: Left ventricular reconstruction surgery is a good surgical option for treatment of post-infarction left ventricular aneurysm.

Keywords: Ventricular restoration surgery; ventricular aneurysms; myocardial infarction; complications

\section{Introduction}

Left ventricular (LV) remodelling occurs following acute myocardial infarction. The progressive LV dilatation, changes to ventricular geometry, and dysfunction that is accompanied by an expansion of myocardial scar [1,2]. This is associated with a poor prognosis [2]. Pharmacological treatment with agents such as angiotensin-converting enzymes inhibitors and beta-blockers are associated with their effects on remodelling. There are various surgical strategies to correct this phenomenon $[3,4]$. The operative strategies have been shown to reduce the left ventricular volume, increase the ejection fraction, and improve cardiac function [5,6]. This is thought to be due to decreasing left ventricular wall tension, improving cardiac haemodynamics, and improving the neurohormonal milieu of patients with heart failure [7]. Currently clinical trials are evaluating the effectiveness of percutaneous strategies to treat ventricular aneurysms $[8,9]$. The Surgical Treatment for Ischemic Heart Failure (STICH) trial was aimed to answer the role of ventricular restoration surgery with or without coronary revascularisation [10]. STICH reported no difference in outcomes for patients undergoing ventricular remodelling surgery. However, STICH findings have been widely criticised and discredited by many authors $[11,12]$. These limitations have led to clinical uncertainty in making such results widely generalizable [13].

We present our contemporaneous series of consecutive patients with ventricular restoration surgery (LVR) that represents an evolution of our clinical practice. LVR was based on a careful evaluation of patients. This included symptoms (heart failure symptoms predominated over angina), measurement of the LV volume and function, and assessment of the extent of myocardial scar tissue.

\section{Methods}

Between 2001 and 2011, 126 consecutive patients underwent LVR. A single surgeon performed $73 \%$ of operations whilst $27 \%$ by two other surgeons. We specifically evaluated early, mid-term and late mortality, procedure specific complications, echocardiograpic and 
clinical outcomes. Most patients had an endoventricular double patch or elliptical patch repair. Large LV cavities required the endoventiruclar (Fontan stitch). Smaller LV cavities had patch placement along line of demarcation of scar tissue followed by linear septal plication. 86 patients had tailored wall excision and septal plication, when indicated, followed by endoventricular patch repair. Gross chamber dilatation and extensive wall motion abnormalities were not considered a contraindication as long as contractile function was preserved in some portion of the ventricle. The extent of asynergy was calculated as a percentage length of the LV perimeter showing a fractional shortening. Extremely poor RV function, synergy of greater than $50 \%$ and pulmonary artery systolic pressure of greater than 60 $\mathrm{mmHg}$ were considered a contraindication for surgery. Coronary angiography provided information on territories for concomitant revascularisation.

In dilated poorly functioning hearts it might be difficult to assess the size and function at the apex by $2 \mathrm{D}$ echocardiography accurately. Ventricular size was assessed on echocardiography with end-diastolic dimension used in all patients along with 3D echo available.

\section{Operative technique}

This series represents an evolution of the operative experience at our unit. The procedure described evolved over time and represents our current surgical philosophy in managing such patients.

The procedure is initially carried out under cardiac arrest with cold blood antegrade cardioplegia and later on with warm blood antegrade cardioplegia. Complete coronary revascularisation is performed with the internal mammary artery always to the Left Anterior Descending (LAD). The ventricle is opened with an incision parallel to the LAD. A sized ventricular shaper (e.g. Mannequin endoventricular shaper, Chase Medical, US) is inserted during the procedure to allow positioning of the new apex, maintain the short to long axis ratio within normal value, provide a more elliptical shape and leave a normal residual chamber size for the patient's body surface area. It also allowed reconstruction of papillary muscles and reconstitution of the mitral valve apparatus. The endoventricular circular suture is performed following the curvature of the shaper and tightening it over the ventricular shaper to leave an appropriately sized cavity. The Dacron patch is tailored to close the opening of the ventricle with an elliptical shape. In cases of the opening being less than $2 \mathrm{~cm}$, the opening is closed with direct suture with Teflon felt reinforcement. The patch is positioned within the cavity to exclude the scarred fibrotic tissue. The patch is placed in an oblique orientation along the upper septal tissue to ensure elliptical alignment. The everting sutures are placed on the patch from septum progressing to the apex while the mannequin is inside. This ensures optimal left ventricular restoration. The mannequin is removed and the patch suture completed. A final LV cavity, which is too small, may result in a low cardiac output state and diastolic dysfunction. The mannequin device filled with appropriate volume and correct positioning of the patch are therefore technically important steps.

Functional mitral regurgitation (MR) complicates ischemic cardiac dysfunction and influences survival [14]. We performed mitral repair in association with LVR in patients with moderate or severe MR and in-cases with annular dilatation or with severely impaired LV. The mitral repair is performed from the LV opening with reduction of the posterior annulus and band annuloplasty.

\section{Follow-up}

All patients were followed up at 8-weeks post-operatively with echocardiography, thereafter by annual assessment at the referring cardiology units with echocardiography. Follow-up was completed by telephone contact with the patient or the patient's family doctor twoyears after the last operation in 2011 of the current series. We assessed the clinical performance and functional score. All patients were placed on beta blockers, ACE-inhibitors, angiotensin II receptor antagomists, loop diuretics and some additionally on potassium sparing diuretics as clinically indicated. All pharmacotherapy was regularly reviewed in outpatient clinics and doses changed according to clinical response to optimise reverse LV remodelling.

\section{Statistical Analysis}

SPSS (IBM Inc. US) was used for statistical analysis. Patient characteristics were compared by means of the t-test for continuous variables and the $\mathrm{x} 2$ test for categorical variables. Results are presented as mean $\pm \mathrm{SD}$. Actuarial survival was calculated by the Kaplan-Meier survival statistic. A good mid-term result is defined as a 5-year survival and long-term as 10-year survival without the need for repeated hospitalisations for heart failure, preservation of LVEF, LV, left atrial dimensions or/and improvement in the New York Heart Association (NYHA) status.

\section{Results}

126 patients with a mean age of 65.4 (44-86) were operated on(M2.3:1F). The co-morbidities are expressed in Table 1.

\begin{tabular}{|l|l|}
\hline Co-morbidities & $\%$ of Patients \\
\hline Age & $65.4(44-86)$ \\
\hline Median pre-op LVEF & 33.1 \\
\hline Logistic EuroScore & $13.83 \%$ \\
\hline Additive EuroScore & $7.29 \%$ \\
\hline Hypertension & $73(58 \%)$ \\
\hline Recent MI (<90 days) & $36(29 \%)$ \\
\hline Diabetes & $18(14 \%)$ \\
\hline Obesity (BMl>35) & $27(21 \%)$ \\
\hline Chronic renal failure & $3(2 \%)$ \\
\hline COPD & $26(20 \%)$ \\
\hline Anatomical location of the aneurysm & \\
\hline Anterio-apical & $85(67 \%)$ \\
\hline Anterio-septal & $19(15 \%)$ \\
\hline Posterio-inferior & $16(12.6 \%)$ \\
\hline Apical & $(4.7 \%)$ \\
\hline
\end{tabular}

Table 1: Demographics, co-morbidities of the patients and preoperative data; COPD: Chronic obstructive pulmonary disease; LVEF: Left ventricular ejection fraction; MI: Myocardial infarction; BMI: Body mass index 
Citation: Attia R, Flemming H, Schulte K, Chambers J, Young C, et al. (2015) Impact of Surgical Ventricular Restoration on Cardiac Function, Ischaemic Mitral Regurgitation and Long-term Survival. J Cardiovasc Dis Diagn 3: 185. doi:10.4172/2329-9517.1000185

Page 3 of 5

All patients with coronary artery disease affecting the LAD (47/126, $37 \%)$ had left internal mammary grafting. $64 / 126,51 \%$ patients had RCA, $67 / 126,53 \%$ circumflex disease. The most common conduit used for the subsequent grafting was long saphenous vein followed by the radial artery in younger patients and those cases with high-grade stenoses. All patients were completely revacularised. The location of the LV aneurysm is shown in Table 1.

The major indications for surgery were multiple. It included class III or IV congestive cardiac failure in all cases. Canadian Cardiac Society (CCS) score III or IV angina in $58 \%$ of cases and ventricular tachycardia in 13/126 (10\%). Double or triple vessel disease was present in most patients 114/126 (90\%). The mean LVEF was $33 \% \pm$ 8.9. Of the patients $96 / 126$ (77\%) had akinesia and remainder had dyskinetic LV segments. The ventricular volume was grossly enlarged with a LVED dimension being greater than $60 \mathrm{~mm}$ in 75/126 (60\%) of cases. The operative procedures that carried out are summarised in Table 2 . The mean cardiopulmonary bypass (CPB) time was $101.3 \pm 63$ minutes and cross clamp time $58.4 \pm 32$ minutes for the cohort. All patients were successfully weaned off from CPB.28/126 (22\%) of cases required inotropic support and 4/126 (3\%) needed an intra-aortic balloon pump for $>48$ hours post-operatively.

\begin{tabular}{|l|l|}
\hline Procedures & \\
\hline CABG+LVR & $101 / 126(80.1 \%)$ \\
\hline Isolated LVR & $8 / 126(6.3 \%)$ \\
\hline CABG+LVR+ASD & $2 / 126(1.6 \%)$ \\
\hline CABG+LVR+VSD & $6 / 126(4.8 \%)$ \\
\hline CABG+LVR+MV repair & $7 / 126(5.5 \%)$ \\
\hline LVR+VSD & $1 / 126(0.8 \%)$ \\
\hline CABG+LVR+AA interposition graft & $1 / 126(0.8 \%)$ \\
\hline Complications & \\
\hline Post-op arrhythmia & $28(22 \%)$ \\
\hline Prolonged inotropes <48 hours & $21(17 \%)$ \\
\hline Chest infection & $18(14 \%)$ \\
\hline Superficial sternal wound infection & $9(7.1 \%)$ \\
\hline IABP (post-op) & $4(3 \%)$ \\
\hline Renal failure & $4(3 \%)$ \\
\hline Stroke & $2(1.6 \%)$ \\
\hline Infection (other) & $2(1.6 \%)$ \\
\hline Resternotomy for bleeding & $1(0.8 \%)$ \\
\hline Permanent pacemaker insertion & $1(0.8 \%)$ \\
\hline
\end{tabular}

Table 2: Operative data; CABG: Coronary artery bypass grafting; LVR: Left ventricular restoration; ASD: Atrial septal defect; VSD: Ventricular septal defect; AA: Ascending aorta

The In-hospital mortality was $7 / 126,5.5 \% .1$ patient had a large ischemic stroke, 1 patient developed ischemic bowel, 1 patient had pulmonary haemorrhage and acute respiratory distress syndrome, 2 patients developed cardiogenic shock and 2 patients died in intensive care at day 22 and 58 with multisystem organ dysfunction. The operative complications are summarised in Table 2 . There was 1 case of permanent pacemaker implantation; there were no cases where cardiac defibrillator for ventricular arrhythmias was required postoperatively.

During follow-up, which extends to ten years there were 18 late deaths. Of these $10(8 \%)$ were cardiovascular. The actuarial survival curve for the entire cohort is shown in Figure 1. Overall survival was $95.3,90.6,86.3$ and 79.1 percent at 1 -month, 1,5 and 10 years.

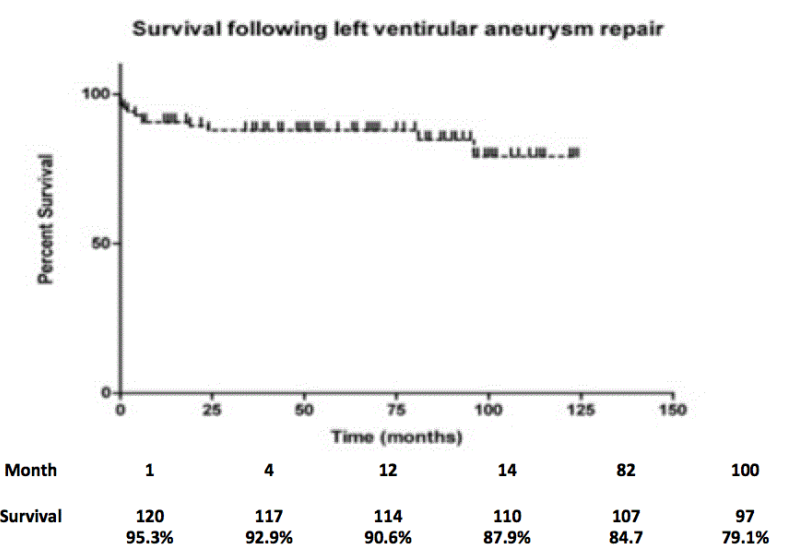

Figure 1: Kaplan Meier Survival Curve demonstrating mid and long-term outcomes following LVR

Among the long-term survivors there was symptomatic improvement in all cases from NYHA III/IV to class I at 6 weeks (80/119, 67\%); class II $(18 / 119,15 \%)$. This improvement was maintained at two, five and ten-year follow-up that was available in $100,95.3$ and 23.6 percent of survivors. The average improvement in symptom class was $1.6 \pm 1.3$ per patient $(\mathrm{P}<0.001)$.

Complete echocardiography data was present in all patients preoperatively. Post-operative echocardiogram was performed at 8 weeks and at 1 year. The mean LVEF improved from $33.1 \% \pm 8.9$ preoperatively to $40.0 \% \pm 8.8$ at 8 weeks $(\mathrm{P}=0.008)$ and $45.0 \% \pm 8.6$ at one-year $(\mathrm{P}=0.006)$. The mean LVEDV decreased from $58.5 \mathrm{~mm} \pm$ 1.07 to $40.4 \mathrm{~mm} \pm 8.8(\mathrm{P}=0.03)$ at 8 weeks and the left atrial diameter decreased from $43.9 \mathrm{~mm} \pm 0.67$ to $40.2 \pm 0.55(\mathrm{P}=0.96)$ at 8 weeks and $38.4 \mathrm{~mm} \pm 0.42(\mathrm{P}=0.02)$ at 1 year. Pre-operatively $77 / 126(61.1 \%)$ of the patients had no MR. 10/126 (8\%)of the patients had +1 MR, 28/126 (22.2\%) had +2 MR, 6/126 (4.7\%) had +3MR and 5/126 (3.9\%) had +4 MR. Post-operatively no patients had grade +3 or +4 MR; whilst $29 / 119$ (30\%) had +1 MR and 6/119 (5\%) had +2 MR. All patients with preoperative moderate to severe structural MR had concomitant mitral valve repair performed.

\section{Discussion}

We present a contemporaneous series of consecutive patients following LVR surgery and report the functional, echocardiographic and survival outcomes in these patients. Our experience represents evolution of the operative technique. The earlier cases had linear resection of scar tissue along line of demarcation and restoration of LV cavity with linear closure technique along healthy tissue. The 
technique was modified as described above over the past five years. The advantage of using a patch technique and the ventricular shaper are accurate estimation of the normal ventricular size and geometry. The wall resection is carried out specifically in each case to accurately preserve the relationship between the septum, papillary muscles, mitral valve apparatus and restore the ventricular geometry. The ventricular shaper volume is kept to at least $50-60 \mathrm{ml} / \mathrm{m}^{2}$ to ensure that LV size is not too small. We carried out the repair in the arrested heart as described by other authors $[4,15]$. As described by Menicanti, Di Donato and Mickleborough et al. we share the philosophy of resecting/ excluding non-functional tissue with plication sutures placed with Teflon felt strips $[13,16]$. We placed a Fontan suture in cases of large LV cavities. In certain cases the repair involves the reconstruction of conical LV apex. LVR is not performed in patients with normal ventricle thickness, as this tissue is likely to remodel with revascularisation alone, even in patients with extremely poor LV function. It is thin infracted scar tissue that forms the substrate for malignant ventricular arrhythmias. These segments are typically akinetic/ dyskinetic requiring resection or exclusion and patch placement.

In considering improvement in functional and echocardiographic outcomes it is important to consider the degree of MR that is present. This was performed in all cases with echocardiography. All patients with structural valve abnormality and moderate to severe $(+3 /+4) \mathrm{MR}$ $(7 / 126,5.5 \%)$ had operative correction as dictated by the valve anatomy. This ranged from annuloplasty, quadrangular resection and sliding plasty, Alfieri repair, chordal reconstruction with neo Gore-Tex chords and re-implantation of the papillary muscles. In our series no patient required mitral valve replacement. In the reminder of 3 patients with moderate MR and those with grade $+2 \mathrm{MR}$ nothing was done to the valve. LV restoration lead to improvement in mitral valve function with no MR in 35/119 (29\%) of cases. MR improved by atleast 1 grade. The reason for this is likely to be decreased annular dilatation as the LV cavity volume is reduced. Improved papillary muscle function due to myocardial revascularisation, realignment of the papillary muscles, chords and the subvalvular apparatus with improved LV geometry. None of the repairs that were performed need to come back for re-operation at our unit during the follow-up out to ten-years.

Myocardial ischemia is a source of ventricular arrhythmias due to progressive LV damage and therefore major cause of morbidity and mortality. We performed complete anatomical revascularisation in all patients who had coronary artery lesions on angiography and more recently were guided by the Fractional Flow Reserve (FFR) [17]. The median number of grafts was 2 , with the internal mammary graft to all cases with LAD lesions. Common second grafts were long saphenous to circumflex or right coronary territories followed by radial artery grafting in high-grade stenoses. In our series 28/126 (22\%) had preoperative ventricular arrhythmias usually in the setting of dilated LV cavity, large anterior-septal scar tissue and poor LVEF. All these patients were post-operative discharged on Amiodarone and assessed for an internal cardioverter-defibrillator device (ICD). None of the patients in this series needed an ICD and ventricular arrhythmias were not a post-operative problem. The strategy of revascularisation, resection and/or exclusion of scar tissue that would act as a substrate for ventricular arrhythmias and diligent follow-up with directed antiarrhythmic treatment and ablation/ICD as needed are effective at preventing arrhythmias. The coronary artery bypass grafting patch trial demonstrated no direct benefit for an ICD in addition to revascularisation in patients with poor LVEF for long-term arrhythmia free survival [18]. It has previously been demonstrated that ventricular arrhythmias are inducible with mechanical loading [19]. Thus LVR would normalise and with time as the LV further remodels reduce the risk of ventricular arrhythmias.

Cardiac synchronisation therapy (CRT) is an alternative treatment strategy that has been advocated in patients with chronic heart failure. This is most commonly achieved through biventricular pacing, but can also be through LV pacing. This is widely accepted as an important adjunct in non-pharmacological treatment of chronic heart failure, through minimising the delay caused by poor LV conditioning. There have been numerous studies including over 15 large randomised controlled trials evaluating the short and mid-term hemodynamic improvements, demonstrating functional recovery and some degree of reverse LV remodelling [20]. The consensus of opinion of the metaanalysis data on CRT is that most trials demonstrate improvements in the patients' symptoms, exercise capacity and reduce hospitalisation. This occurs in patients with NYHA class III/IV symptoms, those with LV aneurysms, LVEF $<35 \%$, and in those with significant electrical conduction delay with a QRS duration $>150 \mathrm{~ms}$. There is conflicting evidence whether CRT prolongs life and influences arrhythmia-related mortality. The current NICE guidelines in the UK incorporate ICD into CRT-P in those patients who do not have a treatable cause of the arrhythmia in the above setting and who demonstrate non-sustained VT on Holter monitoring. Our cohort of patients does not fall into this category as the myocardial revascularisation removes the underlying cause for the ventricular arrhythmia in most patients. LVR provides improvement in functional, symptomatic and echocardiographic outcomes due to LV reverse remodelling, as well as reducing all cause cardiovascular mortality in these patients in the short, mid and longterm.

Various authors have also proposed that along with LV remodelling occurring with time due to revascularisation, the augmentation of ventricular shape has important influence on the function and prognosis. Post-operative magnetic resonance studies have demonstrated reduction in the mean diastolic eccentricity index. Other authors have correlated large residual post-surgery LV enddiastolic volume index as an independent variable of increased mortality and heart failure admissions at up to 2 years follow-up.

In this series a high proportion of patients had multi-vessel coronary artery disease, poor LV function and co-morbidities associated with a poor prognosis. However, the in-hospital mortality was $5.5 \%$ bearing in mind that the Logistical EuroSCORE was $13.8 \%$ for the cohort. The in-hospital mortality in other series varies from 2.8 to $13 \%$, influenced by the case selection, operative techniques, and experience at different units $[4,21,22]$. The five-year survival is similar compared to other published data at $84.7 \%$ with slightly better 10 -year outcomes at $79.1 \%$.

\section{Limitations of the study}

This is a single-centre retrospective experience of prospectively collected consecutive patients. The majority of patients were operated on by a single surgeon (73\%). This represents a select population chosen according to the criteria highlighted above. This series lacks post-operative echocardiographic studies beyond 5-years in most patients. This is necessary for a detailed analysis of changes in LV dimension and function. The availability of the echocardiographic information is limited. We have data on LV systolic function in all patients over time but we have no information on diastolic function 
Citation: Attia R, Flemming H, Schulte K, Chambers J, Young C, et al. (2015) Impact of Surgical Ventricular Restoration on Cardiac Function, Ischaemic Mitral Regurgitation and Long-term Survival. J Cardiovasc Dis Diagn 3: 185. doi:10.4172/2329-9517.1000185

Page 5 of 5

(E/A-ratio, E/E-ratio and E-wave deceleration time over the study period).

\section{Conclusions}

Our findings suggest the importance of an aggressive approach to coronary revascularisation and ventricular restoration in patients with coronary artery disease, poor LV function and large dilated LV cavities. Areas of akinetic or dyskinetic LV wall should be resected/ excluded and ventricular cavity shaped to optimal size. This is to allow myocardial coupling, reduction of LV wall tension and improvement in ejection fraction. This correlates with reduction in the grade of functional MR and clinically improved NYHA class for all patients [23]. If mitral repair is not undertaken there might be an irreversible decline in LV viability, increase in chamber dimensions, wall stress and a poor surgical outcome [24]. Early surgical repair is associated with excellent early, mid and long-term outcomes with low mortality.

\section{References}

1. Mannaerts HF, van der Heide JA, Kamp O, Stoel MG, Twisk J, et al. (2004) Early identification of left ventricular remodelling after myocardial infarction, assessed by transthoracic 3D echocardiography. Eur Heart J 25: 680-687.

2. Cohn JN, Ferrari R, Sharpe N (2000) Cardiac remodeling--concepts and clinical implications: a consensus paper from an international forum on cardiac remodeling. Behalf of an International Forum on Cardiac Remodeling. J Am Coll Cardiol 35: 569-582.

3. Prucz RB, Weiss ES, Patel ND, Nwakanma LU, Baumgartner WA, et al. (2008) Coronary artery bypass grafting with or without surgical ventricular restoration: a comparison. Ann Thorac Surg 86: 806-814.

4. Conte JV (2004) Surgical ventricular restoration: technique and outcomes. Congest Heart Fail 10: 248-251.

5. Menicanti L, Di Donato M (2002) The Dor procedure: what has changed after fifteen years of clinical practice? J Thorac Cardiovasc Surg 124: 886-890.

6. Athanasuleas CL, Buckberg GD, Stanley AW, Siler W, Dor V, et al. (2004) Surgical ventricular restoration: the RESTORE Group experience. Heart Fail Rev 9: 287-297.

7. Di Donato M, Sabatier M, Montiglio F, Maioli M, Toso A, et al. (1995) Outcome of left ventricular aneurysmectomy with patch repair in patients with severely depressed pump function. Am J Cardiol 76: 557-561.

8. Clavel MA, Webb JG, Pibarot P, Altwegg L, Dumont E, et al. (2009) Comparison of the hemodynamic performance of percutaneous and surgical bioprostheses for the treatment of severe aortic stenosis. J Am Coll Cardiol 53: 1883-1891.

9. Clift P, Thorne S, de Giovanni J (2004) Percutaneous device closure of a pseudoaneurysm of the left ventricular wall. Heart 90: e62.
10. Jones RH, Velazquez EJ, Michler RE, Sopko G, Oh JK, et al. (2009) Coronary bypass surgery with or without surgical ventricular reconstruction. N Engl J Med 360: 1705-1717.

11. Buckberg GD, Athanasuleas CL, Wechsler AS, Beyersdorf F, Conte JV, et al. (2010) The STICH trial unravelled. Eur J Heart Fail 12: 1024-1027.

12. Mack MJ (2011) Coronary artery disease: how should the STICH trial results affect clinical practice? Nat Rev Cardiol 8: 427-428.

13. Menicanti L, Castelvecchio S (2011) Left ventricular reconstruction concomitant to coronary artery bypass grafting: when and how? Curr Opin Cardiol 26: 523-527.

14. Yiu SF, Enriquez-Sarano M, Tribouilloy C, Seward JB, Tajik AJ (2000) Determinants of the degree of functional mitral regurgitation in patients with systolic left ventricular dysfunction: A quantitative clinical study. Circulation 102: 1400-1406.

15. Athanasuleas CL, Buckberg GD, Stanley AW, Siler W, Dor V, et al. (2004) Surgical ventricular restoration in the treatment of congestive heart failure due to post-infarction ventricular dilation. J Am Coll Cardiol 44: 1439-1445.

16. Lundblad R, Abdelnoor M, Svennevig JL (2004) Surgery for left ventricular aneurysm: early and late survival after simple linear repair and endoventricular patch plasty. J Thorac Cardiovasc Surg 128: 449-456.

17. Tonino PA, De Bruyne B, Pijls NH, Siebert U, Ikeno F, et al. (2009) FAME Study Investigators. Fractional flow reserve versus angiography for guiding percutaneous coronary intervention. $N$ Engl J Med 360: 213-24

18. Bigger JT (1997) Prophylactic use of implanted cardiac defibrillators in patients at high risk for ventricular arrhythmias after coronary-artery bypass graft surgery. Coronary Artery Bypass Graft (CABG) Patch Trial Investigators. N Engl J Med. 337: 1569-75

19. Di Donato M, Sabatier M, Dor V, Gensini GF, Toso A, et al. (2001) Effects of the Dor procedure on left ventricular dimension and shape and geometric correlates of mitral regurgitation one year after surgery. J Thorac Cardiovasc Surg 121: 91-96.

20. Cleland JG, Daubert JC, Erdmann E, Freemantle N, Gras D, et al. (2005) The effect of cardiac resynchronization on morbidity and mortality in heart failure. N Engl J Med 352: 1539-1549.

21. Lee R, Hoercher KJ, McCarthy PM (2004) Ventricular reconstruction surgery for congestive heart failure. Cardiology 101: 61-71.

22. DiDonato M, Toso A, Dor V, Sabatier M, Menicanti L, et al. (2004) Mechanical synchrony: role of surgical ventricular restoration in correcting LV dyssynchrony during chamber rebuilding. Heart Fail Rev 9: 307-315.

23. DiDonato M, Sabatier M, Dor V, Buckberg G; RESTORE Group (2004) Ventricular arrhythmias after LV remodelling: surgical ventricular restoration or ICD? Heart Fail Rev 9: 299-306.

24. Mickleborough LL, Carson S, Tamariz M, Ivanov J (2000) Results of revascularization in patients with severe left ventricular dysfunction. J Thorac Cardiovasc Surg 119: 550-557. 